\title{
DIREITOS HUMANOS EM TEMPOS DE TERROR ${ }^{1}$ A Segurança Coletiva é a Inimiga da Liberdade Individual? ${ }^{2}$
}

\author{
JUTTA LIMBACH ${ }^{3}$
}

\begin{abstract}
RESUMO: Escolhi um tema que concerne a ambos os nossos Estados - Israel e Alemanha - e que de tempos em tempos coloca um desafio aos nossos tribunais: o respeito aos direitos humanos em tempos de terrorismo. Em Israel, assim como na Alemanha, existe um firme consenso sobre a necessidade de combater o terror. Em ambos há muita controvérsia em relação à melhor maneira de conduzir essa luta. A questão posta é se a segurança coletiva é a inimiga da liberdade individual. Como Aharon Barak corretamente disse: "Lutar contra o terrorismo de um modo eficaz envolve, de um lado, identificar o correto equilíbrio entre segurança e interesse público e, de outro, a necessidade de salvaguardar os direitos humanos e as liberdades fundamentais"4. Esse dilema é bem conhecido do sistema jurídico israelense. Desde a sua fundação, o Estado de Israel tem sido alvo de ameaças contra a sua existência e de terríveis atividades terroristas. Por conseguinte, a experiência israelense - não apenas no campo legal e judicial - é importante para aqueles que estão envolvidos na luta contra o terrorismo. Eu devo agradecer a meu ex-colega Aharon Barak, que me informou regularmente, e, no tocante à minha palestre hoje, sobre as decisões da Suprema Corte referentemente à tortura, à cerca de separação e a outras questões nesse contexto.

PALAVRAS-CHAVE: Terrorismo; Direitos Humanos; Estado de Direito; Direito à
\end{abstract} Segurança; Liberdade Individual.

ABSTRACT: I have chosen a subject that concerns our two states - Israel and Germany - and that time and again poses a challenge to our courts: the respect of human rights in times of terrorism. In Israel as in Germany there exists a firm consensus on the need to fight terror. In both states there is much controversy regarding the best way to conduct this fight. The question is raised whether

Artigo recebido em 27.03.2012. Artigo aceito para publicação em 17.06.2012 mediante convite.

${ }_{1}^{1}$ Este comentário é baseado em uma palestra realizada em Jerusalém em 28 nov. 2007.

2 Título original: Human Rights in Times of Terror - Is Collective Security the Enemy of Individual Freedom. Publicado originalmente no Göttingen Journal of International Law 1 (2009) 1, 17-27. Tradução de Enrique Feldens Rodrigues, Juiz Federal, Especialista em Processo Civil e Mestrando em Direito (Programa de Pós-Graduação em Direito da Faculdade de Direito da PUCRS).

${ }^{3}$ Professora de Direito Civil na Freie Universität Berlin (Universidade Livre de Berlim) desde 1972. De 1989 a 1994 foi Senatorin für Justiz (Secretária de Justiça) em Berlim. Em 1994 foi nomeada ao Bundesverfassungsgericht (Tribunal Federal Constitucional da Alemanha), onde atuou como presidente até 2002. De 2002 a 2008, Jutta Limbach foi a Presidente do Instituto Goethe.

${ }^{4}$ Ahron Barak. Introduction: The Supreme Court and the Problem of Terrorism, in: Israel Supreme Court (ed.). Judgments of the Israel Supreme Court: Fighting Terrorism within the Law, 2005, 5. 
collective security is the enemy of individual freedom. As Aharon Barak rightly stated: "Fighting against terrorism in an effective manner entails finding the right balance between security and public interests, on one hand, and the need to safeguard human rights and basic freedoms, on the other." This dilemma is well known to the Israeli legal system. Since its foundation, the state of Israel has been the target of threats to its existence and of terrible terrorist activities. Therefore the Israeli experience - not only in the legal judicial field - is important for those, who are involved in the fight against terrorism. I have to thank my former colleague Aharon Barak, who informed me regularly, and with regard to my speech today, of the decisions of the Supreme Court concerning torture, the separation fence and other questions in this context.

KEYWORDS: Terrorism; Human Rights; Rule of Law; Right to Security; Individual Freedom.

SUMÁRIO: 1 A Reação do Estado ao Terrorismo; 2 A Caça a Terroristas na Rede de Dados; 3 Um Direito à Segurança; 4 Prevenção versus Liberdade; 5 Os Instrumentos do Estado de Direito; 6 Combatendo o Terrorismo dentro da Lei; 7 Uma Disputa Clássica e Necessária.

SUMMARY: 1 The State's Reaction to Terrorism; 2 The Hunt for Terrorists in the Data Network; 3 A Right to Security; 4 Prevention versus Liberty; 5 The Means of the Rule of Law; 6 Fighting Terrorism Within the Law; 7 A Classical and Necessary Dispute.

\section{A REAÇÃO DO ESTADO AO TERRORISMO}

Sete anos após o 11 de setembro de 2001, a tensão entre liberdade e segurança permanece em contínua atualidade. E não apenas porque os ataques terroristas em Madri e Londres demonstraram que o perigo do terror fanático é onipresente. Um ataque na rede ferroviária alemã, que foi planejado dois anos atrás, mas fracassou, evidenciou que a República Federal da Alemanha também é um alvo dos terroristas extremistas islâmicos.

O que os motiva não é o desejo de retaliação em razão da guerra no Iraque. Os alvos de seus ataques são as seculares democracias ao estilo ocidental, as quais são baseadas nos princípios da dignidade humana, nos direitos fundamentais e no princípio do Estado de Direito. É menos a ânsia de violência e mais propriamente a intenção de destruir esses valores fundamentais que fazem os fanáticos espalhar o medo e o terror com seus ataques a vidas humanas.

Nas democracias ocidentais, políticos estão prestes a cair nessa armadilha e a comprometer as fronteiras dos direitos humanos e das liberdades fundamentais. Com uma visão focada na ameaça posta pelos fanáticos extremistas islâmicos, os políticos argumentam que a Convenção Europeia dos Direitos Humanos ${ }^{5}$ deve ser observada em uma perspectiva diversa. A legislação pós-11/09 na França, no Reino Unido e na Alemanha é justificada com base no dever prevalente de qualquer governo de garantir a

\footnotetext{
${ }^{5}$ Convenção Europeia para a Proteção dos Direitos do Homem e das Liberdades Fundamentais e seus protocolos de 4 de novembro de 1950. 213 U. N. T. S. 222.
} 
segurança de seu povo. Há um direito que importa mais do que qualquer outro, e esse é o direito à vida. A liberdade, nesse contexto, parece ser de menor importância.

Aqui, a vulnerabilidade do Estado livre e democrático calcado no Rule of Law, em tempos de crise, torna-se evidente. Na luta contra o terrorismo, direitos humanos e direitos dos cidadãos foram suprimidos em diversos locais, por todo o planeta.

\section{A CAÇA A TERRORISTAS NA REDE DE DADOS}

No remoto ano de 2002 foi promulgada uma lei na Alemanha com o objetivo de combater o terrorismo. ${ }^{6}$ A lei objetiva pôr fim às atividades de potenciais terroristas tão cedo quanto possível. Esse é apenas o começo. Há uma linha contínua de ativismo político na luta contra o terrorismo. Toda uma séria de leis e novas propostas para tal efeito foram (e têm sido) feitas. O Ministro Federal do Interior, um defensor de rigorosas medidas de precaução, exige o emprego da Bundeswehr (Forças Armadas) no território interno, o assassinato deliberado de terroristas suspeitos e a vigilância de correspondência eletrônica. Um integrante do Bundestag alemão (Parlamento Federal) apela para a criação de um registro de convertidos ao Islã, e o Ministro Federal da Defesa quer ser contemplado com a prerrogativa de ordenar o abate de aviões que são utilizados como armas terroristas.

Se surgem protestos públicos, a respectiva proposição não é mais levada adiante, pois o governo almeja a aprovação do eleitorado. Mas a imaginação política aparece todo o tempo com novas sugestões.

Desde 11/09 a competência das autoridades de segurança foi expandida diversas vezes. Na maioria dos casos, as medidas são secretas; elas permanecem ocultas dos cidadãos. Elas incluem buscas de perfis eletrônicos em computadores, o emprego de agentes secretos, vigilância acústica de residências e a localização de telefones celulares. As pessoas envolvidas não são informadas sobre a vigilância nem antes de depois da medida. Elas, portanto, não podem questionar judicialmente a admissibilidade da medida.

A ação de cunho mais propriamente preventivo é intensificada em um esforço de aumentar a segurança interna do país por meio de métodos como a busca de perfis em computador, agentes secretos e vigilância eletrônica (eavesdropping). O foco foi colocado no combate de crimes, enquanto a utilização do controle judicial voltado para a proteção de suspeitos foi reduzida. Deve-se ter em mente que os métodos modernos de vigilância não monitoram meramente aqueles suspeitos de serem criminosos.

Tome-se, por exemplo, a procura de perfis informatizados na sequência de 11 de setembro. Utilizando um conjunto relativamente abstrato de critérios

6 Gesetz zur Bekämpfung dês internationalen Terrorismus, 9 de janeiro de 2002, (Terrorismusbekämpfungesetz). Bundesgesetzblatt (BGBI.) I 361, 3142. 
(que se restringia a jovens muçulmanos do sexo masculino que viajavam frequentemente e haviam frequentado alguma escola técnica), os dados de um amplo contingente de pessoas que jamais havia tido problemas com a polícia e que não poderiam ser qualificadas como desordeiras ou perigosas foram "filtrados".

Isso tudo demonstra que a busca de perfis informatizados e a vigilância eletrônica podem mesmo trazer pessoas alheias aos fatos para o foco de atenção do investigador. Quanto mais instrumentos de investigação são desenvolvidos para enquadrar quem não tem qualquer envolvimento, mais cedo a categoria da suspeição (concreta) perde seu poder limitante legítimo.

Uma lei que recentemente foi aprovada pelo Bundestag permite a retenção de dados de comunicação. ${ }^{7}$ A lei obriga a todas as companhias de telecomunicação a armazenar os dados de chamadas telefônicas, de e-mails e de tráfego da Internet por seis meses. Essa lei implementa uma diretiva da União Europeia. ${ }^{8}$ No entanto, dois Estados-membros da União Europeia propuseram ação perante o Tribunal de Justiça das Comunidades Europeias buscando o reconhecimento da invalidade da diretiva.

Essa lei irritou não apenas fanáticos por computação. É criticada, com rara unanimidade, sobretudo por jornalistas. Eles temem pelo risco à confidencialidade profissional e pela proteção de suas fontes. Na República Federal da Alemanha, nenhum escândalo foi trazido a público pelos encarregados da persecução criminal; eles tornaram-se acessíveis à imprensa por meio de seus informantes. No futuro, informantes podem ser intimidados por tais leis, que evitariam com que revelassem informações à imprensa. É óbvio o que isso significaria para o controle das autoridades estatais.

\section{UM DIREITO À SEGURANÇA}

Não se tenham dúvidas sobre isto: proteção contra crime e ataques terroristas é parte da responsabilidade do Estado. À luz da ideia reguladora de contrato social, o anseio pela segurança justifica a necessidade do Estado. Os seres humanos unem-se para a proteção mútua de suas vidas, da liberdade e da propriedade dentro de um sistema estatal, e colocam-se sob a égide de um governo. Eles abstêm-se de tomar para si determinadas questões em favor do monopólio estatal do uso da força. Certeza e proteção jurídicas são consequentemente elementos necessários à autorização e à legitimação do Poder Público.

Em oposição à Convenção Europeia de Direitos Humanos, a Constituição alemã $^{9}$ não reconhece o direito à segurança. Apesar do silêncio nessa

${ }^{7}$ Gesetz zur Neuregelung der Telekommunikationsüberwachung umd anderer verdeckter Ermittlungsmaßmahmen sowie zur Umsetzung der Richtlinie 2006 24/EG, 21 de dezembro de 2007, BGBI. I, 3198.

${ }^{8}$ Diretiva 2006/24/EC do Parlamento Europeu e do Conselho, O. J. L105/54 (2006).

${ }^{9}$ Grundgesetz, 23 de maio de 1949, BGBI. I, 1, última emenda, 28 de agosto de 2006, BGBI. I, 2034. 
questão pela Constituição, o Estado tem obrigação de tomar atitudes para garantir a segurança de seus cidadãos por força da lógica subjacente à Constituição, especialmente diante do princípio do Estado de Direito (Rechtsstaatprinzip) e do direito à vida. Por conseguinte, o parlamento e o governo que tentam responder ao perigo do terror cumprem uma atribuição imposta pela Constituição.

\section{PREVENÇÃO VERSUS LIBERDADE}

A questão de se o terror deveria ser combatido não é controvertida. O que o é, entretanto, é como isso deveria ser feito. Como poderíamos encontrar um equilíbrio entre as necessidades de segurança e os direitos humanos dos suspeitos de atividades terroristas?

O conflito entre a segurança coletiva e a liberdade individual suscita a questão: qual desses dois princípios tem prioridade? Em face da nova dimensão do terrorismo e do perigo para a vida e a integridade física de muitas pessoas, o historiador Quentin Skinner argumenta que a primazia da segurança é uma concepção evidente. A metodologia jurídica corretamente alerta para os riscos de se considerar qualquer concepção como evidente. Em muitos casos, concepções que pregam que certas compreensões são óbvias não têm nenhuma função informativa. Elas somente refletem o espírito daqueles que as criaram ou as operaram. Para aqueles que tomam decisões essas concepções meramente servem para resolver seus problemas com fundamento no senso comum, o que quer que senso comum possa significar. Na interpretação de tais máximas, um desconhecido é frequentemente substituído por outro desconhecido.

Nem segurança doméstica como um objetivo do Estado nem os direitos de liberdade individuais devem ser concebidos como preponderantes a priori. O Tribunal Federal Constitucional da Alemanha tem preservado ambos os interesses - as necessidades de segurança e os direitos humanos daqueles suspeitos de atividades terroristas - à luz do princípio do Estado de Direito. A Corte reconhece os interesses mutuamente opostos albergados nesse mesmo princípio constitucional. ${ }^{10}$ Contudo, ressaltar duas de suas facetas contrastantes não nos leva muito longe. A principal questão é ainda deixada sem resposta - nomeadamente se e como um equilíbrio pode ser alcançado entre esses princípios opostos. Uma vez que uma decisão "ou-ou" está fora de questão, a necessidade de segurança coletiva e o direito individual à liberdade devem ser postos de algum modo em relação um com o outro.

\section{OS INSTRUMENTOS DO ESTADO DE DIREITO}

Os juízes não podem cingir-se a descrever o conflito de valores entre segurança e liberdade em frases sonoramente agradáveis. Devem resolver o conflito e, assim o fazendo, devem especificar seus critérios. Se a Constituição

\footnotetext{
${ }^{10}$ Bundesverfassungsgericht (Tribunal Federal Constitucional), BVerfGE 57, 250, 276.
} 
e as medidas legais disponíveis apenas destacam a finalidade abstrata, mas não como pode ser atingida, nada há a fazer para tanto além de listar aqueles aspectos que necessitam ser tomados em consideração quando da compatibilização entre princípios rivais.

O Tribunal Federal Constitucional examina a questão de acordo com os critérios reconhecidos no Estado de Direito, quais sejam, a clareza e a determinação das leis, a adequação (suitability), a necessidade (necessity) e a razoabilidade (appropriateness). A Suprema Corte de Israel, que teve de lidar bem concretamente com as questões da tortura e da cerca de segurança, atua com base nos mesmos princípios. Nos julgamentos de ambas as Cortes, o princípio da proporcionalidade das medidas adotadas ou planejadas desempenha um importante papel.

As medidas antiterror concebidas necessitam ser examinadas em atenção às seguintes questões:

- São efetivamente adequadas para exitosamente combater o terrorismo fanático?

- A resultante perda de liberdade está em proporção com a severidade da intervenção?

- As medidas pretendidas podem resultar em efeitos colaterais indesejados?

Essas três questões não são de forma alguma todas as passíveis de serem formuladas. Mas a principal pergunta é se a legislação pós-11/09 deixou-nos, de fato, mais seguros. A adequação e a proporcionalidade dos instrumentos que são utilizados na luta contra o terrorismo devem ser estritamente revistas. As medidas planejadas devem ser analisadas para identificar se são adequadas para combater com sucesso o terrorismo fanático e se a perda da liberdade que acarretam é proporcional à segurança adquirida por meio delas, sem esquecer as consequências incidentais indesejadas.

Os novos instrumentos legais que vêm sendo introduzidos para combater o tráfico ilegal de drogas e outras formas de crime organizado urgem-nos a conferir especial atenção a essas questões, porque elas usualmente desempenham um papel subordinado no dia-a-dia do trabalho judicial. Na República Federal da Alemanha, a vigilância nos telefones resultou em uma profusão de problemas de informação e linguagem. A profusão de informações também se aplica às buscas em computadores. Em seu último boletim sobre proteção de dados, por exemplo, a Comissária para a Proteção de Dados do Estado da Renânia do Norte-Vestfália comenta criticamente em sua avaliação sobre a busca em computadores realizada na sequência a 11/09 que por meio da busca em computadores milhares de cidadãos inocentes foram colocados no foco da atenção da polícia e foram submetidos a inspeções policiais sem qualquer sucesso mensurável na procura por potenciais terroristas extremistas islâmicos. 


\section{COMBATENDO O TERRORISMO DENTRO DA LEI}

Em Israel, assim como na Alemanha, é tarefa dos juízes proteger os direitos humanos contra as demandas excessivas por segurança. A Suprema Corte de Israel decidiu que interrogadores não podem utilizar tortura a fim de proteger pessoas contra uma situação "bomba-relógio" e que a cerca de segurança, em alguns trechos, é ilegal. Com relação à tortura, a Suprema Corte de Israel enfatizou, de acordo com tratados internacionais, que lançar mão de tratamentos cruéis, desumanos e degradantes é proibido. "Essas proibições são 'absolutas'. Não há exceções para elas e não há margem para balanceamento". ${ }^{11}$ Isso significa: não há espaço para o princípio da proporcionalidade.

O Tribunal Federal Constitucional decidiu que a vigilância acústica da residência não pode invadir a área que compõe o núcleo da vida privada. De acordo com o Tribunal Federal Constitucional, isso resulta da inviolabilidade da dignidade humana. De um modo comparável com a linha de argumentação da Suprema Corte de Israel no tocante à tortura, o Tribunal Constitucional Federal enfatiza o seguinte: aqui um balanceamento de acordo com o princípio da proporcionalidade está fora de questão. ${ }^{12}$

O Tribunal Federal Constitucional tem repetidamente restringido a invasão na liberdade de imprensa e no sigilo das telecomunicações. De acordo com o Tribunal Federal Constitucional, tais invasões são justificáveis apenas se servirem para a persecução criminal no tocante a delitos de considerável importância e caso haja uma suspeita concreta. Deve haver também indicações suficientes e seguras de que existe uma conexão entre a pessoa que é afetada pela medida de vigilância e a pessoa acusada pelo crime. ${ }^{13}$

No concernente a buscas em perfis eletrônicos, o Tribunal Constitucional Federal decidiu que são compatíveis com o direito fundamental à autodeterminação informativa "se há um perigo concreto a importantes bens protegidos juridicamente tais como a existência e a segurança do governo federal ou de um estado, ou a vida, a integridade física e a liberdade de uma pessoa. Com antecedência a atos indicando perigo, buscas de perfis eletrônicos estão fora de questão".

"Uma situação geral de ameaça como a que existe ininterruptamente com respeito a ataques terroristas desde 11 de setembro de 2001, ou situações tensas em política estrangeira, não são suficientes para uma ordem judicial de uma busca de um perfil eletrônico. Ao invés disso, deve haver fatos concretos que indiquem que ataques terroristas estão sendo planejados ou executados". ${ }^{14}$

11 The Israeli High Court of Justice, HCJ 5100/94. The Public Committee Against Torture in Israel v. The State of Israel; reimpresso em: Judgments of the Israel Supreme Court: Fighting Terrorism within the Law 43.

${ }^{12}$ BVerfGE 109, 279.

${ }^{13}$ BVerfGE 107, 229.

${ }^{14}$ BVerfGE 115, 320. 
Nessas decisões, o Tribunal Federal Constitucional também salientou os efeitos colaterais das medidas de segurança. Aponta o seguinte: se cidadãos supõem que órgãos governamentais escutem as suas comunicações, a naturalidade da utilização de modernas tecnologias de comunicação é posta a perigo. Porém também a qualidade da comunicação em determinada sociedade é afetada se o alastramento das medidas investigativas conduz a riscos de mal uso e ao sentimento de estar submetido à vigilância. As medidas jurídicas de precaução criadas para proteger o indivíduo são estabelecidas também em favor da confiança do público em geral. ${ }^{15}$

Em sua decisão sobre a busca em perfis eletrônicos, o Tribunal Federal Constitucional asseverou: "Quem não possa acessar com certeza suficiente quais informações sobre si em determinadas áreas de seu ambiente social são conhecidas e quem não esteja em posição de razoavelmente acessar o que possíveis parceiros de comunicação saibam sobre si pode estar consideravelmente restringido em sua liberdade de planejar e decidir sobre a sua autodeterminação". ${ }^{16}$

"Indivíduos são afetados mais intensamente em sua liberdade que flui de direitos fundamentais quanto menos deram motivos à intervenção estatal. A par disso, tais atos restritivos podem ter efeitos intimidativos os quais podem afetar o exercício de direitos fundamentais. [...] tal efeito deletério deve ser evitado não apenas para proteger o indivíduo. Também afeta o bem comum porque a autodeterminação é a condição básica para o funcionamento de uma sociedade livre e democrática. A naturalidade do comportamento é posta em risco se o alastramento das medidas investigativas contribui a um sentimento de estar sendo mantido sob vigilância". ${ }^{17}$

Como é notório, uma cultura política democrática vive da participação de seus cidadãos e de sua disposição de expressar suas opiniões. Isso requer coragem. Se as autoridades de segurança do Estado avaliam os habitantes do país de acordo com critérios biométricos, se estabelecem perfis de dados sobre eles e se registram suas atividades - tais como, por exemplo, os livros que tomam de empréstimo, a coragem é perdida. Martin Kutscha acertou em cheio quando disse: "Onde quer que um clima de vigilância e espionagem prevaleça, um processo livre e democrático não tem lugar". ${ }^{18}$ Com tais estratégias, um corpo político causa danos a si mesmo. Perde sua credibilidade como um Estado constitucional moderno.

\footnotetext{
${ }^{15}$ BVerfGE 107, 229, 328.

${ }^{16}$ BVerfGE 115, 320, 342.

${ }^{17}$ BVerfGE 115, 320, 354-355.

Martin Kutscha, Mit Riesenschritten auf dem Weg in den Überwachunsstaat. Das Sicherheitspaket der Bundesregiurung: Schutz oder Gefähdung der Demokratie?. Frankfurter Rundschau, (7 de novembro de 2001).
} 


\section{UMA DISPUTA CLÁSSICA E NECESSÁRIA}

A experiência que foi adquirida na persecução dos terroristas da Fração do Exército Vermelho (RAF) na República Federal da Alemanha deveria servir como alerta contra o recurso a políticas simbólicas. Naquela época, a batalha contra o terrorismo da Fração do Exército Vermelho era vista como definidora do destino da República Federal e de sua sobrevivência. O sistema político reagiu com a adoção de medidas perigosamente rápidas, as quais, acima de tudo, sinalizavam atitude, porém mal atingiram a raiz do problema. Ainda assim, apesar de seu reduzido valor prático, as medidas legislativas ainda provaram-se extremamente persistentes.

A despeito de tais experiências, os responsáveis pelas políticas no âmbito interno, as autoridades de segurança e os encarregados da persecução criminal têm sido quase insaciáveis em seu esforço por mais e mais instrumentos e responsabilidades. Esse entusiasmo profissional, que resulta da tarefa que deve ser realizada, somente pode ser mantido sob controle por forças contrárias. Em um Estado de Direito, juízes, advogados e demais órgãos de administração da Justiça são os antagonistas naturais daqueles que são os responsáveis pela segurança doméstica. A disputa entre esses grupos de profissionais é, como aponta Martin Klingst, "tão clássica quanto necessária". ${ }^{19}$ A existência contínua de nosso Estado fundado no império do direito depende também de que os membros do Poder Judiciário não deixem influenciar no seu espírito de resistência e na sua crença nos direitos fundamentais.

Deixemos a Aharon Barak a última palavra:

"Este é o destino de uma democracia que não vê todos os meios como aceitáveis e os métodos de seus inimigos nem sempre como disponíveis. Uma democracia deve às vezes lutar com um braço atado em suas costas. Ainda assim, uma democracia tem a mão superior. O império do direito e as liberdades individuais constituem um importante aspecto de sua instância de segurança. Ao final do dia, eles fortalecem seu espírito e esse reforço lhe permite superar suas dificuldades". ${ }^{20}$

\footnotetext{
${ }^{19}$ Martin Klingst, In der Sicherheitsfalle, Zeit Online, 44 (2001), disponível em: http://www.zeit.de'2001/44/200144_1_leiter.xml. Acessado em 8 ago. 2008.

${ }_{20}$ HCJ 5100/94, The Public Comittee against Torture in Israel v. The State of Israel, 53 (4) PD 817, 854. 